\title{
PENGEMBANGAN DESAIN TEKSTIL 3 BUDAYA DENGAN TEMA ETNIK KONTEMPORER
}

\author{
Isti Kartika ${ }^{1}$
}

\section{ABSTRAK}

Kegiatan membuat celup rintang dilakukan banyak negara di dunia. Sejarah asal-usul teknik ini diperkirakan berasal dari Asia dan berkembang ke wilayah India, bersambung ke wilayah Malaysia. Diperkirakan penyebaran kain ini juga melalui Jalur Sutera. Teknik celup rintang mempunyai beberapa teknik pengerjaan, tetapi masih dalam prinsip yang sama, yaitu merintangi zat warna yang masuk ke beberapa bagian kain. Diantaranya adalah celup ikat atau tie dye, Stitched Resist, Wax Resist. Teknik Pleats merupakan bagian kecil dari sejarah kostum pakaian, pada jaman Mesir kuno pleats telah hadir dengan sebutan "Pleated Kalasiris". Memadukan kedua teknik ini merupakan perpaduan antara budaya barat dan timur, tradisional dan modern, dengan konsep etnik kontemporer.

Kata Kunci: Celup Rintang, Pleats, Pleated Kalasiris, Tie Dye, Stitched Resist, Wax Resist.

\section{ABSTRACT}

Pigment inhibit activities are conducted in many countries in the world. History of the origins of this technique was estimated came from Asia, developed into the territory of India, and continued on the territory of Malaysia. It was estimated that the spread of this fabric through the Silk Road. There are several technical workmanships, but still in the same principle, namely hindering dye into the fabric parts. Among them are tie-dyed or tie dye, Stitched Resist and Wax Resist. Pleats technique is a small part of costume clothes history. In the era of ancient Egypt pleats came with the title "Pleated Kalasiris". Combining these techniques are the combination between western and eastern cultures, traditional and modern, with contemporary ethnic concept.

Keywords: pigment inhibit activity, pleats, pleated kalisiris, tie dye, stitched resist, wax resist

'Isti Kartika : Balai Besar Kerajinan dan Batik Yogyakarta 
Di wilayah Thailand dan Kamboja pun terdapat catatan tentang proses pembuatan kain celup ikat. Diperkirakan bahwa dari negara tersebut teknik celup ikat kemudian menyebar dan memasuki Indonesia yang selanjutnya berkembang ke dalam berbagai bentuk penggunaan.

Bukti tertua dari teknik merintangi dengan lilin atau Wax Resist ditemukan di China pada abad ke10. Dikenal dengan sebutan ladao atau wax-knife technique.

The application of wax-resist before dyeing to form a pattern in negative is most often referred to by the Javanese word batik. Batik is practiced in India, Sri Lanka, China, South-East Asia, Turkestan and West Africa, but in Indonesia, on the island of Java, the craft has been brought to an acme of refnement. Nowhere else has wax-resist cloth been so fnely detailed. The origin of batik are obscure, but what is certain is in that the Javanese invention of the canting waxing instrument enable the fnest hand-drawn batik to be produced. (John Gillow \& Bryan Sentence, 1999: 135)

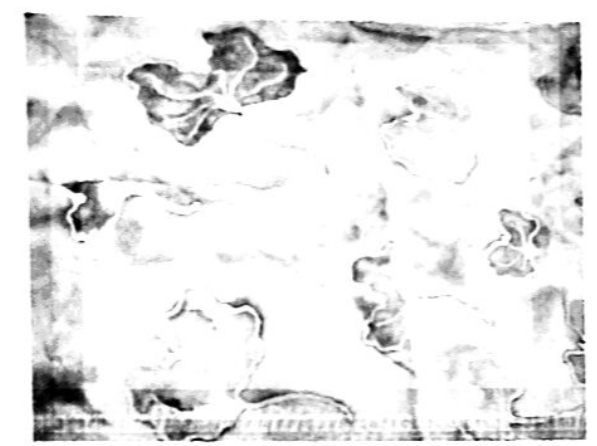

Gambar 2: Silk Painting, Koleksi pribadi

Di belahan dunia utara mengenal pembuatan motif dengan menggunakan teknik melukis di atas kain sutera. atau yang dalam bahasa inggrisnya lebih dikenal dengan Gutta Resist Technique, sebenarnya sudah bukan penemuan baru lagi. Menurut buku Silk Painting (Moyer, 1991), teknik ini ditemukan di Rusia pada awal abad ke-20 dan dipakai oleh kalangan keluarga kerajaan. Mulai menyebar ke perancis dan Hongaria setelah pecah perang yang membuat anggota-anggota keluarga Tsar Rusia berpencar.

Kreatiftas dalam menemukan teknik merintangi warna untuk membuat corak pada kain begitu beragam. Manusia dengan akar budaya masing-masing menemukan cara untuk melestarikan budaya tersebut menjadi benda yang dapat disentuh, dilihat, dirasakan, dinikmati, kemudian dihargai.

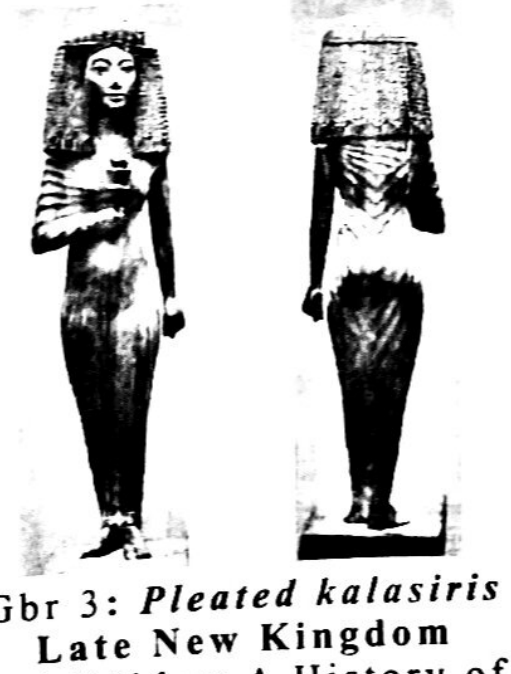

Source: Karl Köhler: A History of Costume 


\section{LATAR BELAKANG}

Terdapat berbagai kebudayaan di dunia dengan berbagai macam keunikan dan karakteristik yang mencirikan kehidupan dari masing-masing daerah asal. Penge, benua Afrika, dan benua Eropa adalah menggabungkan 3 teknik dari 3 benua yaitu, bnya, benua Afrika dengan teknik Pleats, dan Benua Asia yang terkenal dengan teknik celu

Salah satu teknik pembuatan motif pada kain yang paling terkenal di dunia ada di benua Asia, yaitu teknik celup rintang, merintangi zat warna dengan berbagai cara salah satunya teknik membatik, merintangi kain dengan malam. Teknik celup rintang mempunyai be masuk kebeberapa bagian kain masih dalam prinsip yang sama, yaitu merintangi zat wara ya dengan mengikat kain menggunakan Diantaranya adalah celup ikat atau tie dye, merintangi zat wak teknik ini adalah jumputan. Stitched serat atau tali, salah satu kain nusantara yang menggun contoh kain dengan teknik ini terdapat di Resist, merintangi zat warna dengan cara menjahit kain, cesist, merintangi zat warna menggunakan sebagai warisan budaya bukan benda milik Indonesia.

Perkembangan kegiatan membuat celup rintang dilakukan banyak Negara di dunia. Sejarah asal-usul teknik ini diperkirakan berasal dari Asia dan berkembang ke wilayah India, dengan sebutan bhandani, kemudian bersambung ke wilayah Malaysia juga ke benua Afrika. Diperkirakan penyebaran kain ini juga melalui Jalur Sutera, dari Cina sampai ke daratan Persia. Terdapat sejumlah bukti yang menyatakan bahwa kain dengan teknik celup ikat telah dipergunakan pada masa Dinasti T'ang pada abad ke -6 masehi. Pada masa pemerintahan dinasti ini, celup ikat menyebar ke Jepang. Di negeri ini, kain tersebut dinamakan shibori, dan hanya digunakan kaum pendeta dan kaum bangsawan dan terbuat dari sutera.

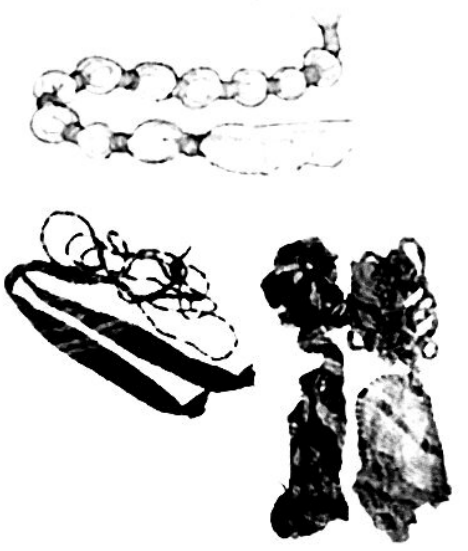

Gambar 1. Turban dalam warna yang cerah. Marwaris mengenalnya dari saudagar Rajasthan pada abad 19 dan permulaan abad 20.

Pengembangan teknik celup ikat,

Di India pada abad ke-6, telah tercatat lukerkembang lebih pesat di India daripada di Jepang. masyarakat tengah memakai kain deangan an pada sebuah gua di Ajanta yang menggambarkan Lukisan pada gua tersebut menggambarkan corak lingaran berwarna putih, yang disebut Pelangi. ukuran. Pada gambar tersebut diuraikan pula proses dengan lingkaran-lingkaran dalam berbagai

30 Dinamika Kerajinan dan Batik, Vol. 27, Juni 2010, hal 29-36 
Teknik pleats merupakan bagian kecil dari sejarah kostum pakaian, pada jaman Mesir kuno pleats telah hadir dengan sebutan "Pleated Kalasiris", yang dibuat dengan menggunakan kleats kemudian satu persatu dengan tangan dan dipersembahkan untuk kaum elite pada dengan wool dan linen.

juga ditemukan di Yunani dengan nama Peplos dan Chic "They wear tunics made of linen with fringes hanging about the legs, called callas cloaks over these."
white woollen
Herodotus, Histories 2,81

Kemajuan teknologi diikuti pula dengan perkembangan life style. Dalam bidang tekstil pun perkembangan life style menuntut kreativitas desainer dalam menciptakan produk fashion atau interior. Tekstil terkadang hanya dilihat secara dua dimensi, selain model, sebag dimensi, permainan melihat dari motif atau warna. Pada dasarnya tekstil pun dapat dilihat secara tiga dimensi, permainan tekstur dapat membuat volume dan kedalaman ruang.

Penggabungan ketiga teknik diatas merupakan penggabungan tiga kebudayaan. Perpaduan east meet west, tradisional dan modern, dua dimensi dan tiga dimensi menghasilkan desain dengan tema etnik kontemporer, serta inovasi dalam desain motif. Produk akhir dari desain ini tidak hanya untuk diversifikasi produk, tetapi lebih kepada pelestarian kebudayaan dengan menghadirkannya dalam balutan moderenitas.

\section{METODOLOGI PENELITIAN}

\section{Perkembangan Teknik Celup Rintang di Indonesia}

Kebiasaan membuat ragam hias sudah dikenal sejak masa pelukisan dinding-dinding gua. Lukisanlukisan ini terdapat di Sulawesi Selatan, Sulawesi Tenggara, P. Muna, P. Seram, P. Kei Kecil, Irian dan Kalimantan. Lukisan- lukisan ini banyak menggambarkan telapak tangan dalam berbagai posisi, alam, binatang dan bentuk geometris. Akan tetapi paling banyak ditemukan gambar terentang telapak tangan pada dinding yang dibubuhi pigmen merah. Perintangan itu secara teknis merupakan tindakan menolak penempelan pigmen merah pada dinding gua. Secara magis pemilihan teknik rintang pigment ( resist dyeing) ditujukan untuk mengundang keterlibatan roh pelindung guna menolak pengaruh roh jahat. Jadi, pemilihan teknik rintang pada tekstil, pada dasarnya dipengaruhi oleh konsep kepercayaan.

Pada dasarnya banyak kain yang diproses menggunakan teknik rintang warna di Indonesia, seperti kain yang menggunakan teknik celup ikat. Kain-kain yang proses pengerjaannya hampir sama dengan batik adalah Kain Simbut dari Banten dan Kain Sarita serta Maa dari Toraja. Kain Simbut adalah kain yang amat tua, dibuat di daerah permukiman Suku Baduy, juga di Jampang Kulon, Selatan Sukabumi. Sebagai perintang digunakan bubur ketan yang dalam bahasa aslinya disebut darih. Sebagai alat pelukis corak digunakan semacam kuas dari buluh kecil. Sedangkan untuk mewarnai keseluruhan kain digunakan kuas dari sabut kelapa. Kini, kain Simbut dapat dikatakan sudah punah dan tidak dibuat lagi. Simbut yang ada sekarang adalah peninggalan masa lalu dan umumnya dianggap benda pusaka untuk keperluan upacara-upacara suci, keagamaan, kelahiran, perkawinan.

Kain Sarita dan Maa lazimnya dikenal sebagai batik Toraja. Media perintang warna yang digunakan adalah malam tawon. Alat pelukisnya sepotong buluh kecil untuk menghasilkan corak-corak geometris, figur-figur manusia, dan binatang. Proses pencelupannya berlangsung sekali saja dalam warna-warna coklat atau biru tua. Kain-kain ini umumnya terbuat dari tenunan tangan dan berukuran lebar $30 \mathrm{~cm}$ atau $60 \mathrm{~cm}$, sedangkan panjangnya bervariasi antara $250 \mathrm{~cm}$ sampai $600 \mathrm{~cm}$. 

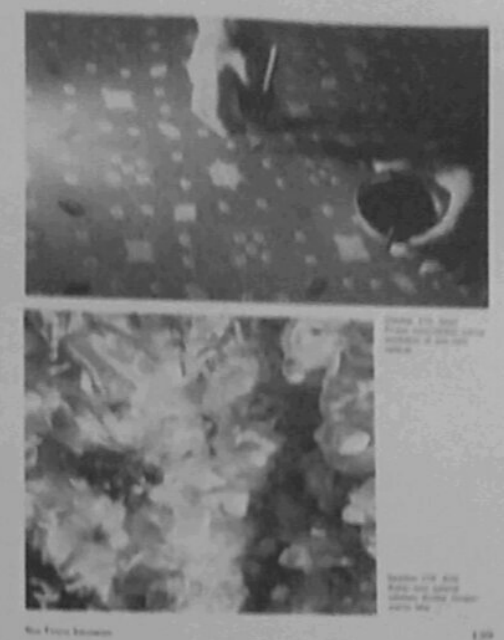

Gambar 4. Kain Pelangi dan Kain Sasirangan. Indonesia Indah vol 4

Di Indonesia terdapat sejumlah daerah pembuat kain celup ikat yang menonjol berikut penamaannya masing-masing. Di daerah palembang, kain celup ikat disebut kain Pelangi atau kain Cinde. Di daerah Banjarmasin, Kalimantan Selatan dikenal kain celup ikat dengan nama kain Sasirangan. Di daerah Yogyakarta, pembuatan kain celup ikat dikenal dengan nama Jumputan atau Tritik. Walaupun letak masing-masing daerah penghasil kain celup ikat tersebut saling berjauhan, pemasarannya tidak terbatas. Seringkali ditemukan kain Pelangi buatan Palembang dipasarkan di daerah Yogyakarta, begitu pula sebaliknya.

\section{Pengembangan Desain 3 Budaya}

Tema untuk karya ini adalah Etnik Contemporer, pemilihan tema ini berdasarkan pada penggunaan teknik produksi, warna, dan desain. Dimana penggabungan teknik tradisional yang disatukan dengan teknik modern sehingga dapat menciptakan sesuatu yang berbeda.

Konsep Etnik Contemporer direpresentasikan pada desain motif bunga, baik pada buketan maupun pada tulip dengan gaya yang simple. Konsep ini juga tampil dalam bentuk karya yang mengambil gaya desain pengaruh luar, kemudian dipadukan dengan teknik pewarnaan tradisional serta teknik pleats yang memberikan sentuhan modern.

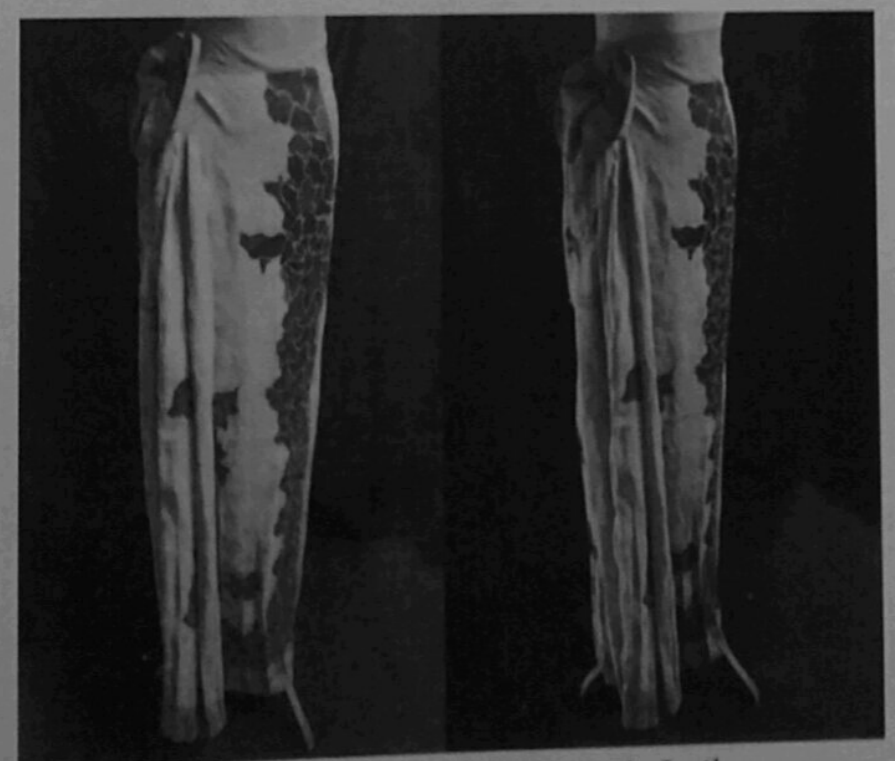

Gambar 4: Karya dalam bentuk Jarik 
bentuk karya fahion maupun interior. Pemilihan jenis kain yang berbeda bertujuan untuk memperlihatkan keunikan setiap bahan setesoris busana, dan sarung. sama. Pada produk fashion diwujudkan dalam bentuk tidur, dan lampu sudut.

pemilihan desain, warna dan efek tekstur Nilai estetik terlihat dari penggunaan bahan yang beragam, peterang menghasilkan efek membentuk yang dihasilkan dari teknik pleats. Permainan warna gembentuk tekstur, memberikan efek timbul. bidang, ruang, ataupun kedalaman. Permainan garn efek 3 dimensi dalam permainan tekstur. tenggelam. Penambahan aksen warna, memberikan efek 3 dimensi dalam

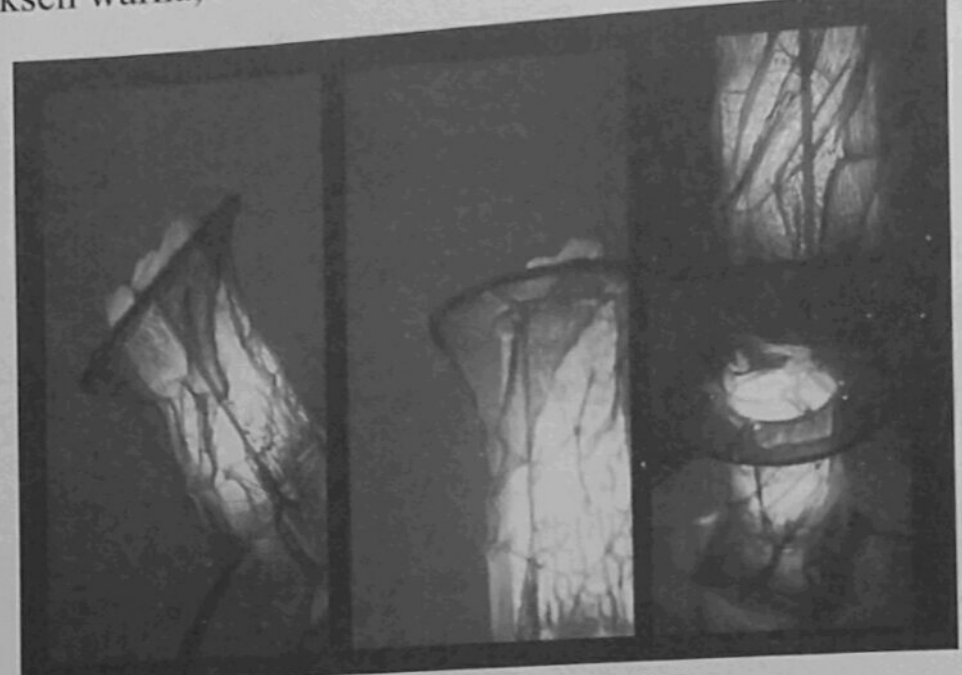

Gambar 5: Karya dalam bentuk Lampu

Pada karya interior nilai fungsional sebuah lampu adalah memberikan penerangan pada tempattempat tertentu. Pada lampu sudut diberikan warna yang tidak banyak menahan cahaya lampu atau warna kain yang cerah, seperti putih, sehingga ruangan tetap dalam keadaan semi terang atau pemakai masih dapat menggunakan ruangan tersebut untuk membaca. Lampu sudut ini cocok untuk ruang tamu, ruang keluarga ataupun ruang makan. Pemilihan warna dalam karya lampu tidur cenderung gelap atau warna yang dapat menahan cahaya lampu agar dapat menghasilkan cahaya yang temaram, sehingga pemakai dapat beristirahat dengan nyaman.

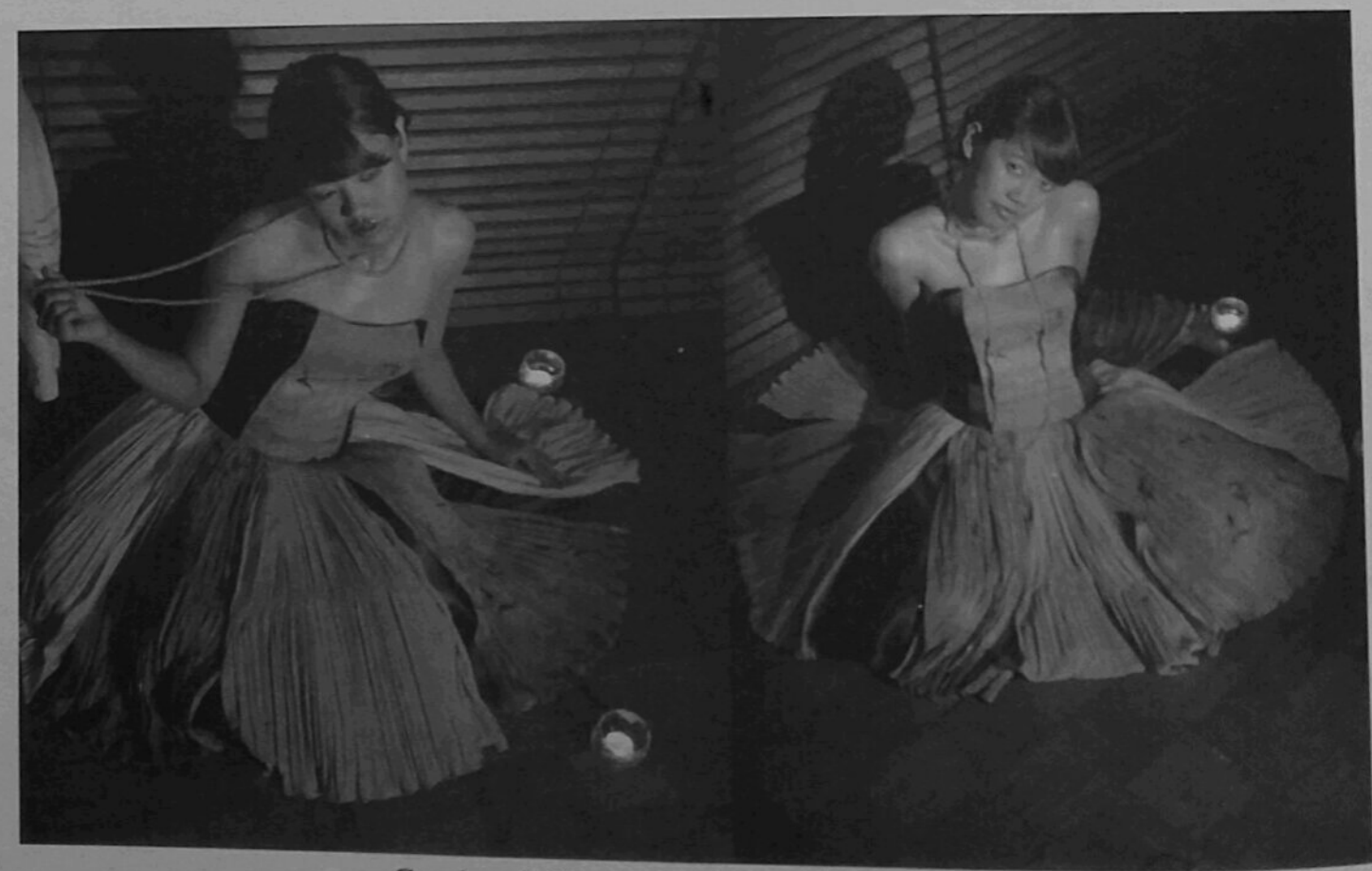

Gambar 6: Karya dalam bentuk Tube dress 
Pada karya fashion, tube dress dapat digunakan untuk acara-acara formal, seperti cocktail party, wedding party, ataupun Prom Night (malam wisuda). Sarung, dapat digunakan untuk acara-acara formal seperti, wedding party atau acara-acara lain yang perlu menggunakan pakaian tradisional.

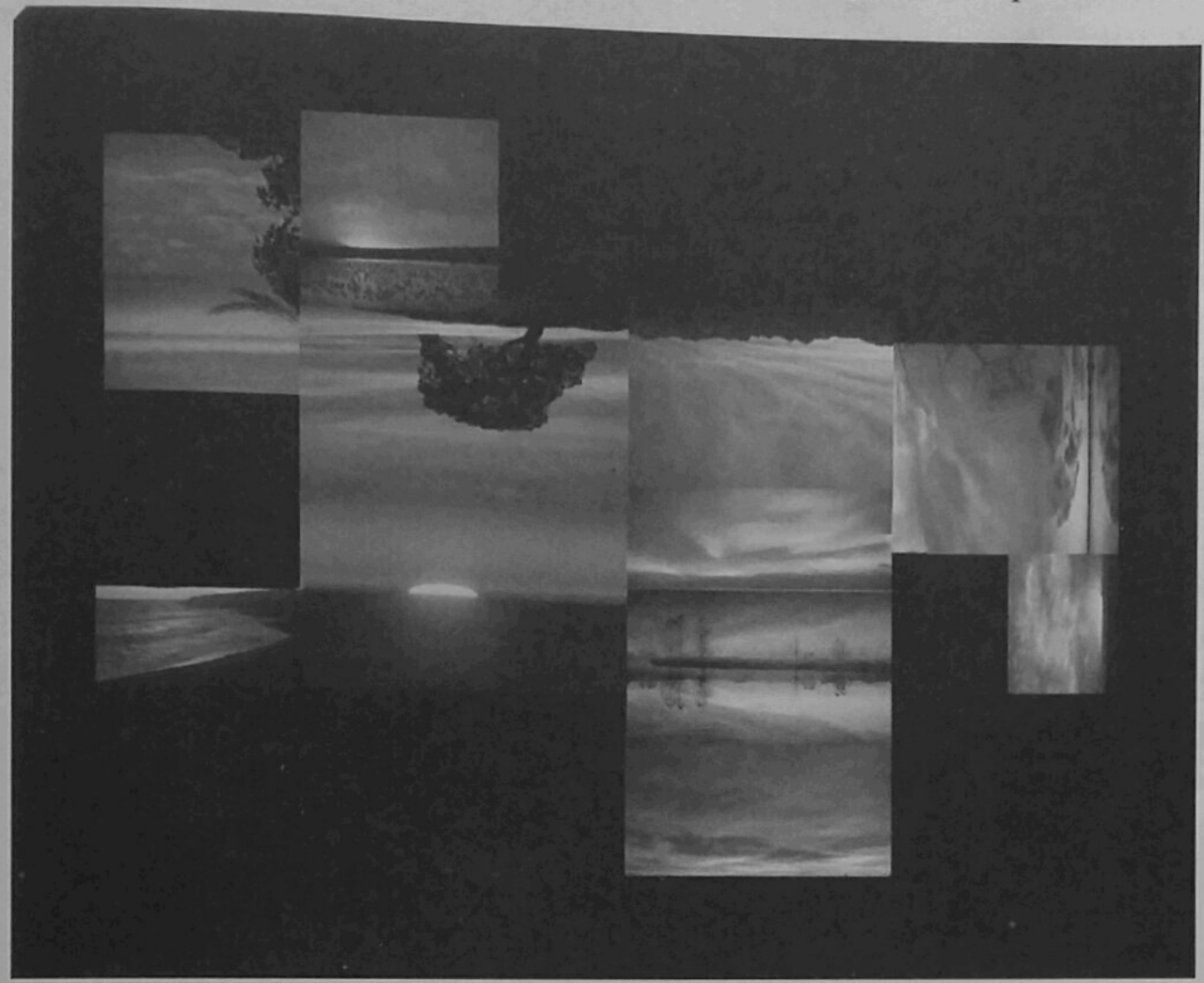

Gambar 6: Image Board

Pemilihan warna desain diambil dari warna langit di pagi dan sore hari, sunrise dan sunset. Suasana ketika matahari terbit dan tenggelam mempunyai beragam warna seperti biru, ungu, merah, kuning, dan orange. Pemilihan warna-warna pada karya dari warna yang ringan atau cerah, hingga warna berat atau gelap, memberikan efek timbul tenggelam atau membentuk ruang dalam bidang. Gradasi yang timbul pada saat matahari terbit ataupun terbenam menciptakan beragam efek warna yang menambah nilai estetika.Tema Etnik Contemporer pada sarung ditampilkan oleh warna-warna yang eye-catching diatas background dengan warna lembut.

\section{KESIMPULAN DAN SARAN}

\section{Kesimpulan}

Berdasarkan data-data sejarah diatas penggabungan 3 kebudayan dari 3 benua Asia, Afrika, dan Eropa dapat menghasilkan inovasi desain yang sangat indah. Hal ini sekaligus melestarikan 3 budaya dalam balutan moderenitas sehingga memberikan pangsa pasar yang lebih luas bagi produsen baik dari segi usia, daerah pemasaran, gender, serta status sosial.

\section{Saran}

Sejarah ada agar manusia tidak mengulangi kesalahan dan memberikan pengetahuan untuk sesuatu yang telah ada. Budaya ada agar manusia tidak melupakan akar kehadiran mereka di muka bumi. Kreatiftas ada untuk menggabungkan keduanya kemudian menghadirkan inovasi.

"Anyone who thinks the sky is the limit, has limited imagination." 
DAFTAR PUSTAKA

Alwi, H et al. 2001. Kamus Besar Bahasa Indonesia. Jakarta: Balai Pustaka.

Conventary, L, Nixon, M.1999. The Oxford English Mini Dictionary. Oxford University Press Inc. New York.

Cowan, M.L,1962. Introduction to Textiles. Appeton-Century-Crofts Inc. New York.

Gillow, J; Sentence, B.1999. World Textile. Thames \& Hudson. London.

Suara Pembaruan, Minggu 6 Januari 2002, Artikel BinHouse

Trocmé, S. 2002. Fabric. Octopus Publishing Group Ltd. Great Britain.

Yayasan TMII, 1997. Indonesia Indah, Volume 8 (Batik), Jakarta

Yayasan TMII, 2000. Indonesia Indah, Volume 4 (Kain-kain Non Tenun Indonesia). Jakarta 